\title{
Cervical Cerclage for Pregnant Women at High-risk of Recurrent Preterm Birth can Act Beyond its Mechanical Action
}

\author{
Original \\ Article \\ Wagdy M. Amer', Ali A. Morsi ${ }^{1}$, Hamasat A. Alnoury ${ }^{2}$ \\ ${ }^{\prime}$ Department of Obstetrics and Gynecology, ${ }^{2}$ Department of Clinical and Chemical pathology, \\ Faculty of Medicine, Benha University, Egypt.
}

\begin{abstract}
Aim: Evaluation of predictive value of levels of cervicovaginal fluid (CVF) interleukin (IL)-6 and 8, and matrix metalloproteinases (MMP) estimated at time of performing cervical cerclage (CC) in women with history of spontaneous preterm birth (SPTB) for pregnancy duration.

Materials and Methods: 59 women had history of SPTB (Study group) and 25 women with no history of SPTB (Control group). Two CVF samples were obtained for ELISA estimation of IL-6, IL-8, MMP8 and MMP9 levels at 14-18 gestational weeks (GW), S1 sampling time, and at time of removal of CC suture, S2 sampling time. CC was applied 4-days after S1 sampling.

Results: S1-CVF levels were significantly higher in study versus control women. S2-CVF levels were significantly higher in control, while were significantly lower in study women compared to S1 levels. S2-CVF IL-6 and IL-8 levels were nonsignificantly higher, while levels of MMP were significantly lower in study than control women. Percentages of change in cytokines' levels showed significant differences between study and control groups. Nineteen study women had PTD at $<37$ $\mathrm{GW}$, while 40 women had labor at $>37 \mathrm{GW}$. Study women had significantly shorter CL and pregnancy duration compared to control women. Pregnancy duration was negatively correlated with percentage of CL change, while positively correlated with percentage of decrease of cytokines levels.

Conclusion: CC induced significant decrease of CVF cytokines' levels and allowed prolongation of pregnancy duration for $>37 \mathrm{GW}$ in $67.8 \%$ of studied women at high risk of SPTB
\end{abstract}

Key Words: Cervicovaginal fluid, inflammatory cytokines, preterm birth, pregnancy duration

Received: 06 May 2021, Accepted: 06 May 2021

Corresponding Author: Wagdy Amer, Department of Obstetrics and Gynecology, Faculty of Medicine, Benha University, Egypt, Tel.: 01005636992, E-mail: wagdyamer524@gmail.com

ISSN: 2090-7265, May 2021, Vol.11, No. 2

\section{INTRODUCTION}

Cervical insufficiency (CI) is a condition of pregnancy which causes the cervix to soften, shorten and dilate between 18 and 22 gestational weeks $(\mathrm{GW})^{[1]}$ and is an important cause of preterm birth $(\mathrm{PTB})^{[2]}$. The World Health Organization and the United Nations consider PTB as a major factor for the global rates of neonatal death and to longer-term health problems for surviving infants ${ }^{[3]}$.

Etiology of CI and the subsequent spontaneous PTB (SPTB) is multifactorial ${ }^{[4]}$. High cytokine concentrations that were detected during pregnancy indicated that pregnancy is associated with an active inflammatory state $^{[5]}$. Disturbed plasma inflammatory markers in early pregnancy were associated with decreased cervical length (CL) and suggest an impact of imbalance of immune regulation on $\mathrm{CL}^{[6]}$. The levels of inflammatory proteins in the cervicovaginal fluid (CVF) were found to be correlated with inflammatory proteins in the amniotic fluid (AF), but not with that in the plasma ${ }^{[7]}$ and indicates disturbed local immune balance in female genital organs mostly towards the inflammatory side ${ }^{[8]}$. The optimum method of collection of CVF in pregnant women for cytokine measurement is unknown; however, both polyvinyl acetal sponge collection of cervical fluid and menstrual cup collection of CVF are robust for measurement of local cytokines during pregnancy ${ }^{[9]}$.

Cervical cerclage (CC) is currently one of the primary methods of CI treatment ${ }^{[10]}$. Progesterone preparations have different efficacy in prevention of PTB prior to $37 \mathrm{GW}$ in women at risk ${ }^{[11]}$. Vaginal progesterone effectively allowed prolonged duration of pregnancy in nullipara women pregnant in singleton fetus with $10-20 \mathrm{~mm} \mathrm{CL}$ in the midtrimester ${ }^{[12]}$, but was not effective in twin pregnancy ${ }^{[13]}$.

Hypothesis : This study hypothesized that disturbed levels of cytokines in the CVF have a role in the initiation of cervical incompetence (CI) with subsequent spontaneous PTB (SPTB), but cervical cerclage (CC) may act beyond its mechanical role for prolongation of duration of pregnancy through an effect on CVF cytokine milieu.

\section{AIM OF WORK}

Estimation of levels of interleukin- 6 and 8, and matrix metalloproteinases (MMP) in CVF in women with past history of SPTB in comparison to normal pregnant women 
at time of performing $\mathrm{CC}$ (S1 sampling time) and removal of CC suture (S2 sampling time).

\section{PATIENTS AND METHODS}

This is a prospective comparative interventional study concuded at University Hospital, Benha, Egypt and multiple private obstetrics centers

All pregnant women who presented to the Antenatal Care Unit (ACU) with past history of SPTB were eligible for evaluation for inclusion and exclusion criteria. Inclusion criteria included pregnancy with singleton fetus, past history of SPTB secondary to CI, GA $>12$ $\mathrm{GW}$ and absence of exclusion criteria. Exclusion criteria included manifest diabetes mellitus, multiple pregnancy, and presence of pregnancy-induced complications and/or vaginal infection. Also, women lost during follow-up or gave pregnancy out of participating centers were excluded from the study. The study also included 25 age-matched normal pregnant women free of history and signs of SPTB, and exclusion criteria, and presented at the same GA as control group. The study protocol was approved by the Local Ethical Committee and all enrolled women signed written fully informed consent.

At time of presentation demographic and clinical data of enrolled women were obtained and at time of performing the $\mathrm{CC}$, all women were re-evaluated and CVF samples were obtained. Then, all women undertook transvaginal ultrasonography (TVU) for estimation of CL; women had $\mathrm{CL}<25 \mathrm{~mm}$ were considered at high-risk for $\mathrm{SPTB}^{[14]}$ and underwent Shirodkar's cervical cerclage within 4 days after CVF sampling (S1 sampling time) and were considered as Study group. All enrolled women were maintained on vaginal toilet to guard against development of infection. Women of the study group were asked to attend the ACU biweekly for follow-up for development of SPTB, which was defined as any birth before 37 weeks completed weeks of gestation ${ }^{[15]}$. At time of labor or removal of the suture, women of both groups undertook CVF sampling (S2 sampling time) for re-estimation of CVF cytokines' levels and the percentage of change in CVF cytokines' levels was calculated as the percentage of difference between levels estimated in both samples multiplied by $100(\%$ of change $=([$ S1-S2 levels $] /[S 1$ level] $] *(100))$.

\section{CVF sample obtaining and processing :}

Vaginal speculum was placed and the cervix visualized. An ectocervical sample was collected by sweeping the cervix $360^{\circ}$ and maintained in situ for 30 seconds to maximize saturation. On removal of the cervical swab, a Dacron swab was swept $360^{\circ}$ in vaginal vault and posterior vaginal fornix, and maintained in situ for 10 seconds to achieve saturation. Then, swabs were transferred into 750 $\mathrm{ml}$ of standard phosphate-buffered saline solution mixed with freshly prepared protease inhibitor solution. The swab was then removed, placed in a clean tube, vortexed for 10 $\mathrm{sec}$ and centrifuged at $2500 \mathrm{~g}$ for 10 minutes, at $4^{\circ} \mathrm{C}$ and the resulting fluid was collected and added to the fluid in the original tube, well-mixed and centrifuged for a further 10 minutes to remove cell debris. Cell-free supernatants were collected and divided into aliquots and stored at $-80^{\circ} \mathrm{C}$ until being ELISA assayed ${ }^{[16]}$.

\section{Investigations}

CVF levels of IL- 6 and -8 and matrix metalloproteinases (MMP) were measured using ELISA kits according to the manufacturer's instructions and were read using a 96 well microplate ELISA reader (Dynatech, MR 7000). Human IL-6 was measured with the enzyme linked immunoassay (ELISA) kit (catalogue No IL631-K01; Eagle Bioscience Inc., USA) which employs the quantitative sandwich enzyme immunoassay technique ${ }^{[17]}$. Human IL-8 was measured with the enzyme linked immunoassay (ELISA) kit (catalogue no. ab46032, abcam Inc., Cambridge, USA) which employs the quantitative sandwich enzyme immunoassay technique ${ }^{[18]}$. Human Matrix metalloproteins $8^{[19]}$ and $9^{[20]}$ was measured with the enzyme linked immunoassay (ELISA) kit (catalogue no. ab181421 and ab100610, abcam Inc., Cambridge, USA) by quantitative sandwich enzyme immunoassay technique.

\section{Cervical cerclage}

Cervical cerclage was performed using the Shirodkar procedure with a non-absorbable suture at GA of 14-18 GW and within 4 days after S1 sampling time. After performing $\mathrm{CC}$, women were asked to avoid any sexual activity, use of tampons or douching, prolonged standing for $>4 \mathrm{~h}$, heavy physical work, lifting heavy weights, straining or any activity that brings on symptoms of pelvic pressure or discomfort.

Study Outcomes : Primary outcome includes the effect of pregnancy on the CVF cytokines' levels. Secondary outcomes included the effect of cerclage on CL and CVF cytokines' levels in women of study group as well as the value of early estimation of CVF cytokines' levels as predictors for pregnancy duration.

\section{STATISTICAL ANALYSIS}

Obtained data were presented as mean $\pm \mathrm{SD}$, numbers and percentages. Results were analyzed using paired t-test, One-way ANOVA Test and Chi-square test ( $\mathrm{X}^{2}$ test). Possible relationships were investigated using Pearson linear regression analysis. Predictability of S1-CVF cytokines' levels for pregnancy duration was evaluated by Regression analysis (Stepwise method) and receiver operating characteristic (ROC) curve analysis, judged by the area under the curve (AUC) that was compared versus null hypothesis that $\mathrm{AUC}=0.5$. Statistical analysis was conducted using the IBM SPSS (Version 23, 2015; IBM, South Wacker Drive, Chicago, USA) for Windows statistical package. $P$ value $<0.05$ was considered statistically significant. 


\section{Results}

Seventy-five women with past history of SPTB were eligible for evaluation; 16 women were excluded for not fulfilling inclusion criteria and 59 were included in the study as study group. Twenty-five women with no history of SPTB were also enrolled as control group (Figure 1).

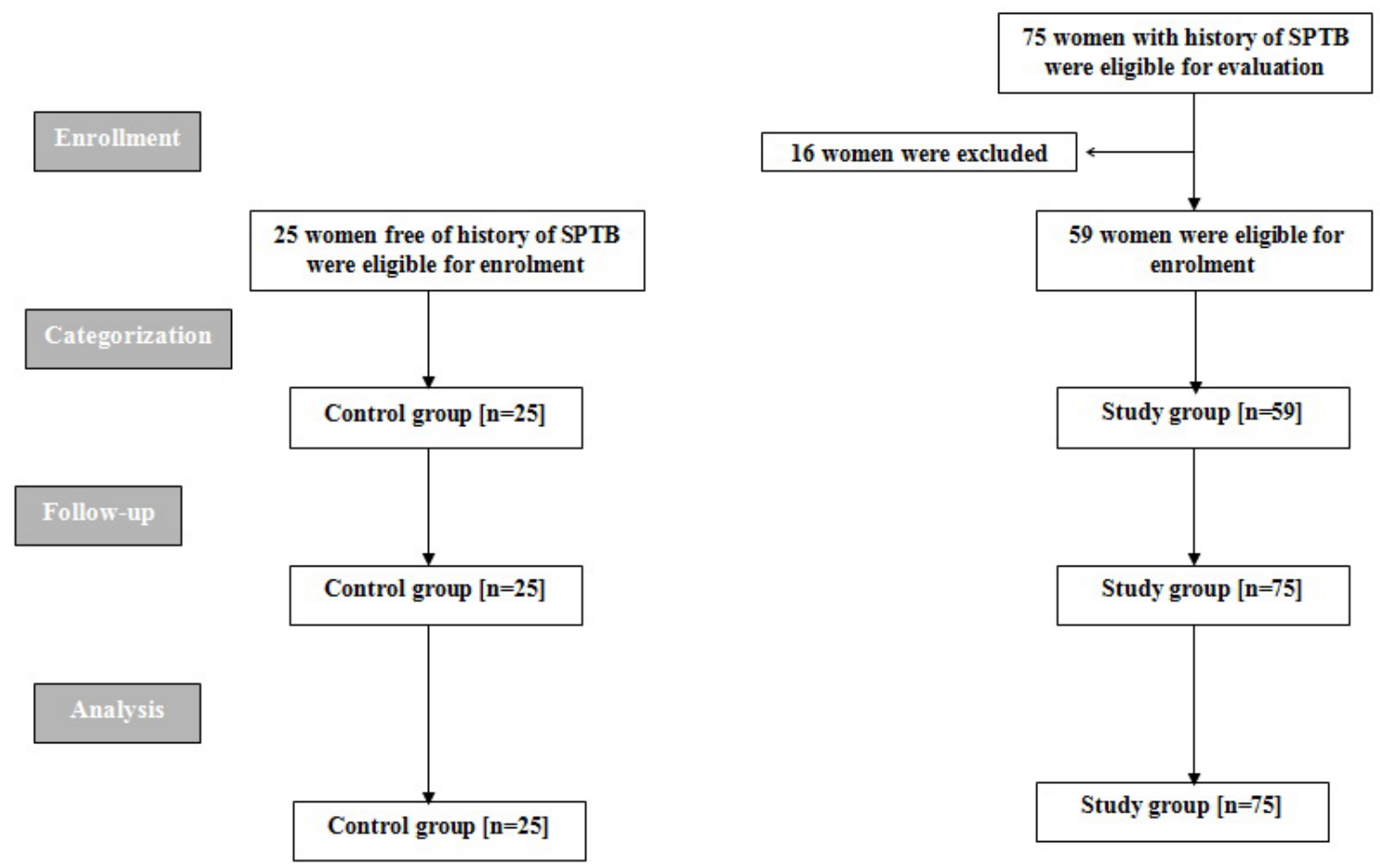

Fig.: Consort Flow sheet

Women's enrollment data showed non-significant $(p>0.05)$ differences between both groups apart from the number of women had prior early pregnancy loss that was significantly $(\mathrm{p}=0.02)$ higher in women of study group compared to women of control group (Table 1).

Table 1: Enrolment data of women of both groups

\begin{tabular}{|c|c|c|c|c|}
\hline Data & Group & Control $(n=25)$ & Study $(\mathrm{n}=59)$ & Pvalue \\
\hline \multicolumn{2}{|l|}{ Maternal age (years) } & $28.5 \pm 5.5$ & $28.2 \pm 2.7$ & 0.673 \\
\hline \multicolumn{2}{|c|}{ Gestational age at time of enrolment (wks) } & $16.4 \pm 2.1$ & $16.2 \pm 2.3$ & 0.713 \\
\hline \multicolumn{2}{|l|}{ Body weight (Kg) } & $86 \pm 8.5$ & $87 \pm 7.1$ & 0.578 \\
\hline \multicolumn{2}{|l|}{ Body height $(\mathrm{cm})$} & $170 \pm 4.6$ & $169.8 \pm 3.1$ & 0.831 \\
\hline \multicolumn{2}{|c|}{ Body mass index $\left(\mathrm{Kg} / \mathrm{m}^{2}\right)$} & $29.8 \pm 3.1$ & $30.2 \pm 3$ & 0.578 \\
\hline \multirow{3}{*}{ Obstetric history } & Gravidity & $2.4 \pm 0.6$ & $2.5 \pm 0.7$ & 0.533 \\
\hline & Parity & $1.4 \pm 0.6$ & $1.3 \pm 0.9$ & 0.578 \\
\hline & Prior early pregnancy loss & $3(12 \%)$ & $7(22 \%)$ & 0.020 \\
\hline \multirow{4}{*}{ General exam } & Systolic blood pressure $(\mathrm{mmHg})$ & $113.2 \pm 4.8$ & $114.2 \pm 3.7$ & 0.278 \\
\hline & Diastolic blood pressure $(\mathrm{mmHg})$ & $73.8 \pm 8$ & $72.4 \pm 4.6$ & 0.324 \\
\hline & Heart rate (beat/min) & $94.72 \pm 5.7$ & $93.7 \pm 4$ & 0.351 \\
\hline & Body temperature $\left({ }^{\circ} \mathrm{C}\right)$ & $36.5 \pm 0.4$ & $36.6 \pm 0.3$ & 0.195 \\
\hline \multirow{3}{*}{ Lab findings } & Total leucocytic count $\left(\times 10^{3} / \mathrm{mm}^{3}\right)$ & $11.43 \pm 1,0 \wedge$ & $11.21 \pm 1.76$ & 0.587 \\
\hline & C-reactive protein $(\mathrm{mg} / \mathrm{L})$ & $4.65 \pm 2.4$ & $5.12 \pm 3$ & 0.487 \\
\hline & Fasting blood glucose (mg/dl) & $93 \pm 11$ & $97.3 \pm 9.3$ & 0.071 \\
\hline
\end{tabular}


Data are presented as mean $\pm \mathrm{SD}$, numbers, percentages; $\mathrm{p}$ value indicates significance of difference between both groups; $p<0.05$ indicates significant difference; $p>0.05$ indicates non-significant difference

The mean level of S1-CVF cytokines was significantly higher in women of study group in comparison to women of control group. At time of labor, all women of control group had significantly higher S2-CVF cytokines' levels in comparison to their S1-CVF levels. On the other hand, in women of study group, S2-CVF cytokines' levels were significantly lower compared to their corresponding S1CVF levels. Moreover, mean S2-CVF levels of IL-6 and IL-8 were non-significantly higher, while mean levels of MMP were significantly lower in studied women compared to control women. Subsequently, the percentages of change in CVF cytokines' levels showed significant differences between both groups (Table 2).

Table 2: Levels of studied cytokines estimated in S1 and S2 samples obtained from women of both group

\begin{tabular}{|c|c|c|c|c|c|c|c|}
\hline \multirow[b]{2}{*}{ Variables } & \multirow[t]{2}{*}{ Group } & \multicolumn{3}{|c|}{ Control } & \multicolumn{3}{|c|}{ Study } \\
\hline & & S1 sample & S2 sample & $\%$ of change & S1 sample & S2 sample & $\%$ of change \\
\hline \multirow{3}{*}{ IL-6 (ng/ml) } & Concentration & $5.12 \pm 1.68$ & $6.92 \pm 1.88$ & $37.46 \pm 9.8$ & $10.62 \pm 2.4$ & $7.21 \pm 2.05$ & $-32.64 \pm 8.53$ \\
\hline & $\mathrm{P} 1$ & & 0.0008 & & & $<0.0001$ & \\
\hline & $\mathrm{P} 2$ & & & & $<0.0001$ & 0.544 & $<0.0001$ \\
\hline \multirow{3}{*}{ IL-8 (ng/ml) } & Concentration & $7.78 \pm 2.04$ & $10.9 \pm 2.6$ & $42.3 \pm 15.5$ & $15.25 \pm 6$ & $11.12 \pm 3.6$ & $-25.3 \pm 6.9$ \\
\hline & $\mathrm{P} 1$ & & $<0.0001$ & & & $<0.0001$ & \\
\hline & $\mathrm{P} 2$ & & & & $<0.0001$ & 0.777 & $<0.0001$ \\
\hline \multirow{3}{*}{ MMP9 (ng/ml) } & Concentration & $39.9 \pm 12.1$ & $52.2 \pm 19.9$ & $39.8 \pm 16.9$ & $54.8 \pm 17.8$ & $40.6 \pm 16.5$ & $-22.2 \pm 7.6$ \\
\hline & $\mathrm{P} 1$ & & $<0.0001$ & & & $<0.0001$ & \\
\hline & $\mathrm{P} 2$ & & & & 0.0003 & 0.0008 & $<0.0001$ \\
\hline \multirow{3}{*}{ MMP8 (ng/ml) } & Concentration & $63.5 \pm 18.6$ & $92.4 \pm 33.7$ & $46.5 \pm 26$ & $104.1 \pm 23.2$ & $78.4 \pm 20.6$ & $-24.8 \pm 9.2$ \\
\hline & $\mathrm{P} 1$ & & 0.0001 & & & $<0.0001$ & \\
\hline & $\mathrm{P} 2$ & & & & $<0.0001$ & 0.014 & $<0.0001$ \\
\hline
\end{tabular}

P1: indicates the significance of difference in concentration of CVF cytokines in S1 and S2 samples; P2: indicates the significance of difference between estimated CVF cytokines' concentrations in control and study groups

Nineteen women of study group had PTD after a mean duration of pregnancy of $35.3 \pm 0.9 \mathrm{wk}$, while 40 women of study group had onset of labor that required cerclage suture removal after a mean duration of pregnancy $38.5 \pm 0.7 \mathrm{wk}$. Mean duration of pregnancy of study women was $37.5 \pm 1.7$ wk with significantly $(p=0.0003)$ shorter pregnancy duration compared to control women $(39.1 \pm 0.7 \mathrm{wk})$. All women of study group showed shortening of the CL at S2-sampling time compared to S1-sampling time with a mean decrease of CL by $20.7 \pm 4.9 \%$. Women who had PTD had significantly $(p=0.017)$ higher percentage of decrease of CL $(22.9 \pm 4.4 \%)$ compared to percentage of decrease in women who had labor after $37 \mathrm{GW}(19.6 \pm 4.9 \%)$.
Pregnancy duration of study women showed negative significant correlation $(\mathrm{r}=-0.340, p=0.008)$ with the percentage of change in CL, while showed positive significant correlation with the percentage of change of CVF levels of IL-6 ( $\mathrm{r}=0.473, p=0.0004)$, IL-8 ( $\mathrm{r}=0.396$, $p=0.002)$, MMP8 $(\mathrm{r}=0.382, p=0.003)$ and MMP9 $(\mathrm{r}=0.347$, $p=0.007$ ) between $\mathrm{S} 1$ and $\mathrm{S} 2$ samples.

Regression analysis for S1-CVF cytokines' levels defined elevated levels of IL-8 ( $\beta=-0.386, p=0.0003)$, IL-6 ( $\beta=-0.362$, $p=0.0008)$, MMP8 $(\beta=-0.284, p=0.003)$ and MMP9 $(\beta=-0.244$, $p=0.007$ ) as predictors for short duration of pregnancy. ROC curve analysis defined elevated S1-CVF levels of MMP9 as a sensitive predictor for short duration of pregnancy (Figure 2).

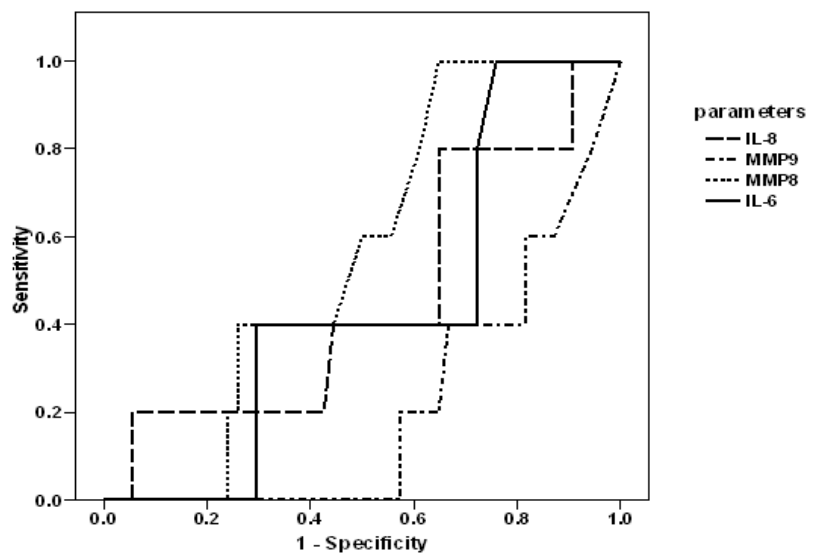

Fig. 2: ROC curve analysis of lab parameters as predictors for short duration of pregnancy 


\section{DISCUSSION}

The obtained results showed a significant increase of S2-CVF cytokines' levels in control women compared to S1-CVF levels, this finding indicates that pregnancy induces an inflammatory status and its progress is associated with shift of local cytokine milieu towards the inflammatory arm. Moreover, the increased levels at time of labor indicated that the process of delivery itself requires or amplify such inflammatory status.

These findings go in hand with Basu et al. ${ }^{[21]}$ who experimentally found villous MMP-9 protein increased progressively with increased gestational age and a positive correlation between villous tumor necrosis factor- $\alpha$ (TNF- $\alpha$ ) and MMP-9 in $2^{\text {nd }}$ trimester placenta of normal gestation, so attributed successful pregnancy outcome to such relations. Recently, Buxton et al..$^{[5]}$ detected progressively increasing concentrations of cytokines in CVF samples collected monthly from two-to-nine months of gestation among term pregnancies and documented that pregnancy is associated with an active inflammatory state.

Mean S1-CVF cytokines' levels were significantly higher in women who were at high risk of SPTB (Study group) compared to women of control group who had full term delivery. These findings spots light of a possible etiological role of disturbed local cytokines' milieu for development of CI with subsequent SPTB. In line with these findings, Monsanto et al..$^{[22]}$ detected higher levels of IL-1 $\beta,-6$ and 12 , monocyte chemoattractant protein-1 and TNF- $\alpha$ in CVF of women had CI compared to control pregnant women and suggested that CI may be associated with or develops secondary to dysregulation of the local immune environment. Also, Ashford et al. ${ }^{[23]}$ found the CVF values of IL- 6,8 and 10 , TNF- $\alpha$, and CRP and serum MMP-8 were significantly higher in women who had preterm birth (PTB) than the full-term women.

In support of the etiopathological role of inflammatory cytokines in development of PTB, As Sayaril et al. ${ }^{[24]}$ reported higher expression of genes for IL1 $\alpha$, IL-1 $\beta$, IL-6, and TNF- $\alpha$ in plasma of PTB patients than in control pregnant women. Recently, Song et al. ${ }^{[25]}$ detected positive correlations between amniotic fluid (AF) hypoxia-inducible factor $1 \alpha$ (HIF1 $\alpha$ ) and exosomal HIF $1 \alpha$ with AF levels of IL- $1 \alpha$, IL-6, and TNF- $\alpha$ in CI patients with physical examination-indicated cerclage and suggested an interaction between AF HIF $1 \alpha$ and exosomes and inflammatory cytokines that may induce or contribute the inflammatory cascade in complicated pregnancies.

Cervical cerclage (CC) induced significant reduction of S2-CVF cytokines' levels compared to S1-CVF levels and the percentage of decrease correlated positively with the duration of pregnancy with significantly lower percentage of decrease in women had PTB $(<37 \mathrm{GW})$ compared to women had pregnancy duration of $>37 \mathrm{GW}$. These findings are consistent with that of Monsanto et al. ${ }^{[22]}$ who found cerclage intervention led to a significant decline in CVF proinflammatory cytokines levels and suggested that cerclage may help reduce local inflammation in women had CI.

In support of the efficacy of $\mathrm{CC}$ as a preventive therapeutic modality for PTB, Wang et al. ${ }^{[26]}$ found $\mathrm{CC}$ is more beneficial for better pregnancy outcome than vaginal progesterone therapy for women with an asymptomatic short cervix and prior PTB history. Also, Sinkey et al. ${ }^{[27]}$ found that in women with CI combined CC and intramuscular progesterone resulted in PTB prevention similar to cerclage alone. Moreover, Caritis et al.$^{[28]}$ reported significantly elevated levels of IL- 6 and 10 , and TNF- $\alpha$ in cervical fluid of women had their prior PTB between 16 and 23 weeks than those had prior PTB between 32 and 36 wks and treatment with 17-hydroxyprogesterone caproate had no significant impact on these cytokines.

Regression analysis defined high S1-CVF levels of IL-6 and IL- 8 as the most significant predictors, while ROC curve analysis defined high S1-CVF level of MMP8 as the significant sensitive predictor for short duration of pregnancy. Similarly, Ashford et al..$^{[23]}$ documented that the levels of IL- $1 \alpha$, IL- 6 , TNF- $\alpha$ can be used as predicative biomarkers for PTB. Also, Park et al. ${ }^{[29]}$ reported that plasma and AF IL-6 levels had an overall diagnostic performance to predict imminent PTB and Garry et al. ${ }^{[30]}$ reported increased presence of IL-1 $\alpha$, IL-1 $\beta$, IL-2 and IL-13 in vaginal washings of women at risk for PTB. Moreover, Liu et al. ${ }^{[31]}$ found high AF TNF- $\alpha$ and IL-8 levels before CC affect pregnancy outcome in women with CI and levels higher than $3.58 \mathrm{ng} / \mathrm{ml}$ and $0.105 \mathrm{ng} /$ $\mathrm{ml}$ of IL- 8 and TNF- $\alpha$, respectively could predict perinatal death of the infants.

\section{CONCLUSION}

Pregnancy induces an inflammatory state that shifts towards the inflammatory arm with the progress of pregnancy. CI and short CL with subsequent PTB are associated with early higher levels of inflammatory cytokines in CVF. Cervical cerclage induced significant decrease of CVF cytokines' levels, allowed prolongation of pregnancy duration for more than $37 \mathrm{GW}$ in $67.8 \%$ of studied women at high risk of SPTB.

\section{CONFLICT OF INTERESTS}

There are no conflict of interests.

\section{REFERENCES}

1. Baumer $\mathrm{A}^{1}$, Gimovsky $\mathrm{AC}^{2}$, Gallagher $\mathrm{M}^{2}$, Leftwich MC: A synthetic cervix model and the impact of softness on cerclage integrity. Interface Focus. 2019 Oct 6; 9(5):20190009. doi: 10.1098/rsfs.2019.0009.

2. Raia NR, Bakaysa SL, Ghezzi CE, House MD, Kaplan DL: Ex vivo pregnant-like tissue model to assess injectable hydrogel for preterm birth prevention. J Biomed Mater Res B Appl Biomater. 2019 May 9. doi: 10.1002/jbm.b.34403. 
3. Medley $\mathrm{N}^{1}$, Vogel JP, Care A, Alfirevic Z: Interventions during pregnancy to prevent preterm birth: an overview of Cochrane systematic reviews. Cochrane Database Syst Rev. 2018; 11:CD012505. doi: 10.1002/14651858.CD012505.

4. Manning $\mathrm{R}$, James $\quad \mathrm{CP}^{2,3}$, Smith $\quad \mathrm{MC}^{1}$, Innes $\mathrm{BA}^{1}$, Stamp $\mathrm{E}^{4}$, Peebles $\mathrm{D}^{2}$, Bajaj-Elliott $\mathrm{M}^{3}$, Klein $\mathrm{N}^{3}$, Bulmer $\mathrm{JN}^{1}$, Robson $\mathrm{SC}^{1}$, Lash GE: Predictive value of cervical cytokine, antimicrobial and microflora levels for pre-term birth in high-risk women. Sci Rep. 2019 Aug; 9(1): 11246. doi: 10.1038/ s41598-019-47756-7.

5. Buxton $\mathrm{MA}^{1}$, Meraz-Cruz $\mathrm{N}^{2}$, Sánchez $\mathrm{BN}^{3}$, Foxman $\mathrm{B}^{4}$, Gronlund $\mathrm{CJ}^{5}$, Beltran-Montoya $\quad \mathrm{J}^{6}$, CastilloCastrejon $\mathrm{M}^{1}$, O’Neill $\mathrm{MS}^{1,4}$, Vadillo-Ortega $\mathrm{F}$ : Repeated Measures of Cervicovaginal Cytokines during Healthy Pregnancy: Understanding "Normal" Inflammation to Inform Future Screening. Am J Perinatol. 2019 Apr 12. doi: 10.1055/s-0039-1685491.

6. Venkatesh KK, Cantonwine DE, Ferguson K, Arjona M, Meeker JD, McElrath TF: Inflammatory and oxidative stress markers associated with decreased cervical length in pregnancy. Am J Reprod Immunol. 2016; 76(5):376-382. doi: 10.1111/ aji.12545.

7. Lee $\mathrm{SM}^{1,2}$, Park $\mathrm{KH}^{1,3}$, Jung $\mathrm{EY}^{1,3}$, Kook SY, Park $\mathrm{H}$, Jeon SJ: Inflammatory proteins in maternal plasma, cervicovaginal and amniotic fluids as predictors of intra-amniotic infection in preterm premature rupture of membranes. PLoS One. 2018; 13(7):e0200311. doi: 10.1371/journal.pone. 0200311 .

8. Heng YJ, Liong S, Permezel M, Rice GE, Di Quinzio MK, Georgiou HM: Human cervicovaginal fluid biomarkers to predict term and preterm labor. Front Physiol. 2015; 6:151. doi: 10.3389/fphys.2015.00151. eCollection 2015 .

9. Short CS, Quinlan R, Bennett P, Shattock RJ, Taylor GP: Optimising the collection of female genital tract fluid for cytokine analysis in pregnant women. J Immunol Methods. 2018; 458:15-20. doi: 10.1016/j. jim.2018.03.014

10. Kanninen TT, Sisti G, Di Tommaso M, Berghella $\mathrm{V}$ : The role of predictive vaginal biomarkers in women with cervical cerclage. J Matern Fetal Neonatal Med. 2018; 31(13):1792-1797. doi: $10.1080 / 14767058.2017 .1326895$.
11. Krispin E, Hadar E, Chen R, Wiznitzer A, Kaplan B: The association of different progesterone preparations with preterm birth prevention. J Matern Fetal Neonatal Med. 2019; 32(20):3452-3457. doi: $10.1080 / 14767058.2018 .1465555$.

12. Maerdan M, Shi C, Zhang X, Fan L: The prevalence of short cervix between 20 and 24 weeks of gestation and vaginal progesterone for prolonging of gestation. J Matern Fetal Neonatal Med. 2017; 30(14):1646-1649. doi: $10.1080 / 14767058.2016 .1220528$

13. Azria E: The use of progestatives for the prevention of spontaneous preterm birth. J Gynecol Obstet Biol Reprod (Paris). 2016; 45(10):1280-1298. doi: 10.1016/j.jgyn.2016.09.012.

14. Owen J, Yost N, Berghella V, Thom E, Swain M, Dildy GA 3rd, Miodovnik M, Langer O, Sibai B, McNellis D; National Institute of Child Health and Human Development, Maternal-Fetal Medicine Units Network: Midtrimester endovaginal sonography in women at high risk for spontaneous preterm birth JAMA. 2001; 286(11):1340-8.

15. Meher S, Alfirevic Z: Choice of primary outcomes in randomised trials and systematic reviews evaluating interventions for preterm birth prevention: a systematic review. BJOG. 2014; 121(10):1188-94; discussion 1195-6. doi: 10.1111/1471-0528.12593.

16. Jung EY, Park KH, Han BR, Cho SH, Ryu A: Measurement of Interleukin 8 in cervicovaginal fluid in women with preterm premature rupture of membranes: A Comparison of Amniotic Fluid Samples. Reprod Sci. 2017; 24(1):142-147. doi: 10.1177/1933719116651149.

17. Gaines-Das RE, Poole S: The international standard for interleukin-6-evaluation in an international collaborative study. J Immunol Methods. 1993; 160: 147-53.

18. Dembinski J, Behrendt D, Heep A, Dorn C, Reinsberg J, Bartmann P: Cell-associated interleukin- 8 in cord blood of term and preterm infants. Clin Diagn Lab Immunol. 2002; 9(2):320-3.

19. Biggio JR Jr, Ramsey PS, Cliver SP, Lyon MD, Goldenberg RL, Wenstrom KD: Midtrimester amniotic fluid matrix metalloproteinase-8 (MMP8) levels above the $90^{\text {th }}$ percentile are a marker for subsequent preterm premature rupture of membranes. Am J Obstet Gynecol. 2005; 192(1):109-13. 
20. Lin D, Alborn WE, Slebos RJ, Liebler DC: Comparison of protein immunoprecipitationmultiple reaction monitoring with ELISA for assay of biomarker candidates in plasma. J Proteome Res. 2013 Dec 6; 12(12):5996-6003. doi: 10.1021/pr400877e

21. Basu J, Agamasu E, Bendek B, Salafia CM, Mishra A, Lopez JV, Kroes J, Dragich SC, Thakur A, Mikhail M: Correlation Between Placental Matrix Metalloproteinase 9 and Tumor Necrosis Factor- $\alpha$ Protein Expression Throughout Gestation in Normal Human Pregnancy. Reprod Sci. 2018; 25(4):621-627. doi: $10.1177 / 1933719117725819$.

22. Monsanto SP, Daher S, Ono E, Pendeloski KPT, Trainá É, Mattar R, Tayade C: Cervical cerclage placement decreases local levels of proinflammatory cytokines in patients with cervical insufficiency. Am J Obstet Gynecol. 2017; 217(4):455.e1-455.e8. doi: 10.1016/j. ajog.2017.06.024.

23. Ashford K, Chavan NR, Wiggins AT, Sayre MM, McCubbin A, Critchfield AS, O'Brien J: Comparison of Serum and Cervical Cytokine Levels throughout Pregnancy between Preterm and Term Births. AJP Rep. 2018; 8(2):e113-e120. doi: 10.1055/s-00381656534 .

24. As Sayaril N, Bhat RS, Warsy AS, Babay ZA, Addar MH, Shaik J, Al-Marry B, Al-Daihan S: Polymorphisms in proinflammatory cytokine genes, effect on gene expression and association with preterm delivery in Saudi females. Cell Mol Biol (Noisy-legrand). 2018; 64(10):55-60.

25. Song JE, Park SJ, Lee KY, Lee WJ: Amniotic fluid HIF $1 \alpha$ and exosomal HIF $1 \alpha$ in cervical insufficiency patients with physical examination-indicated cerclage. J Matern Fetal Neonatal Med. 2019; 32(14):22872294. doi: 10.1080/14767058.2018.1432037
26. Wang SW, Ma LL, Huang S, Liang L, Zhang JR: Role of Cervical Cerclage and Vaginal Progesterone in the Treatment of Cervical Incompetence with/without Preterm Birth History. Chin Med J (Engl). 2016; 129(22):2670-2675. doi: 10.4103/0366-6999.193451.

27. Sinkey RG, Garcia MR, Odibo AO: Does adjunctive use of progesterone in women with cerclage improve prevention of preterm birth? J Matern Fetal Neonatal Med. 2018; 31(2):202-208. doi: $10.1080 / 14767058.2017 .1280019$.

28. Caritis SN, Hankins G, Hebert M, Haas DM, Ahmed M, Simhan H, Haneline LA, Harris J, Chang J, Famy AS, Yorio P, Ren Z, D'Alton ME, Venkataramanan R: Impact of Pregnancy History and 17-Hydroxyprogesterone Caproate on Cervical Cytokines and Matrix Metalloproteinases. Am J Perinatol. 2018; 35(5):470-480. doi: 10.1055/s-00371608631

29. Park H, Park KH, Kim YM, Kook SY, Jeon SJ, Yoo $\mathrm{HN}$ : Plasma inflammatory and immune proteins as predictors of intra-amniotic infection and spontaneous preterm delivery in women with preterm labor: a retrospective study. BMC Pregnancy Childbirth. 2018; 18(1):146. doi: 10.1186/s12884-018-1780-7.

30. Garry DJ, Baker DA, Persad MD, Peresleni T, Kocis C, Demishev M: Progesterone effects on vaginal cytokines in women with a history of preterm birth. PLoS One. 2018 Dec 31;13(12):e0209346. doi: 10.1371/journal.pone.0209346. eCollection 2018.

31. Liu YL, Feng ZY, Tan JP, Zhu LQ, Zhang JP: Relationship between inflammatory indexes of amniotic fluid and pregnancy outcome of women with cervical incompetence. Zhonghua $\mathrm{Fu}$ Chan Ke Za Zhi. 2018; 53(8):517-521. doi: 10.3760/cma.j.issn.0529-567x.2018.08.002. 